Research, Society and Development, v. 9, n.10 e8389107905, 2020

(CC BY 4.0) | ISSN 2525-3409 | DOI: http://dx.doi.org/10.33448/rsd-v9i10.7905

\title{
As indústrias têxteis da Bahia: o ontem e o hoje
}

Bahia's textile industries: yesterday and today

Las industrias textiles de Bahia: ayer y hoy

Recebido: 26/08/2020 | Revisado: 01/09/2020 | Aceito: 19/10/2020 | Publicado: 21/10/2020

Bruna Silva Matos

ORCID: https://orcid.org/0000-0002-1828-0624

Centro Universitário UNIFTC, Brasil

E-mail: bruna98matos@gmail.com.br

Jerisnaldo Matos Lopes

ORCID: https://orcid.org/0000-0002-3921-3631

Centro Universitário UNIFTC, Brasil Universidade Estadual da Bahia, Brasil

E-mail: jerislopes@hotmail.com

Rosângela Moreira de Oliveira

ORCID: http://orcid.org/0000-0003-2113-9274

Centro Universitário UNIFTC, Brasil

Universidade Salvador, Brasil

E-mail: rosamoadm@outlook.com

\section{Resumo}

Sendo de grande importância para o âmbito econômico-social, as indústrias fazem parte das discussões referenciadas ao desenvolvimento de um país ou região. As indústrias têxteis foram as primeiras a enquadrar-se no setor econômico primário, no Brasil. Especificamente na Bahia, essas fábricas tiveram papel importante no desenvolvimento do estado, de forma a destacar-se das demais. Porém, houve muitas ocasiões de altos e baixos do poder industrial baiano. O objetivo desse trabalho é realizar um estudo exploratório das primeiras indústrias do ramo têxtil na Bahia instaladas no final do século XIX, como exemplo notório a Fábrica Todos os Santos, ainda em atividade, contextualizar como se deu o crescimento dessa indústria, assim como quais os principais aspectos do crescimento econômico dos séculos XIX e XX. A realização da pesquisa foi conduzida com metodologia por meio de análises que têm como base levantamento de referencial teórico de autores de referência em desenvolvimento regional, revolução industrial e suas mais diversas indústrias de 
beneficiamento, de forma a reunir conhecimento sobre o tema e mostrar como a industrialização na Bahia influenciou no desenvolvimento do estado. Sendo os resultados caracterizados por meio de dados extraídos de pesquisa utilizando como fonte o banco de dados da Relação Anual de Informações Sociais (RAIS), do Ministério do Trabalho e Emprego, com objetivo de levantar informações sobre a indústria têxtil na Bahia no período de 1985 a 2018, e sendo concluído ao demonstrar os estudos e esforços despendidos para conhecimento do assunto relacionando os cenários passados frente ao cenário atual.

Palavras-chave: Indústria têxtil; Revolução Industrial; Desenvolvimento regional; Bahia.

\begin{abstract}
Being of great importance for the economic-social scope, as the industries are part of those referenced to the development of a country or region. The textile industries were the first to fit into the primary economic sector in Brazil. Specifically in Bahia, these factories play an important role in the development of the state, in order to stand out from the others. However, there were many occasions of ups and downs in Bahian industrial power. The objective of this work is to carry out an exploratory study of the first textile industries in Bahia installed at the end of the 19th century, as a notable example the Fábrica Todos os Santos, still in operation, to contextualize how the growth of this industry took place, as well as which main aspects of economic growth in the 19th and 20th centuries. The research was conducted with methodology through analyzes that are based on a survey of the theoretical framework of reference authors in regional development, industrial revolution and its most diverse processing industries, in order to gather knowledge on the subject and show how the industrialization in Bahia influenced the development of the state. The results are characterized by data extracted from research using the database of the Annual List of Social Information (RAIS), of the Ministry of Labor and Employment, with the objective of gathering information about the textile industry in Bahia, in the period of 1985 to 2018, and concluding by demonstrating the studies and efforts spent on knowledge of the subject, relating the scenarios to the current scenario.
\end{abstract}

Keywords: Textile industry; Industrial Revolution; Regional development; Bahia.

\title{
Resumen
}

Siendo de gran importancia para el ámbito económico-social, ya que las industrias forman parte de las referidas al desarrollo de un país o región. Las industrias textiles fueron las primeras en encajar en el sector económico primario de Brasil. Específicamente en Bahía, 
estas fábricas juegan un papel importante en el desarrollo del estado, para diferenciarse de las demás. Sin embargo, hubo muchas ocasiones de altibajos en el poder industrial bahiano. El objetivo de este trabajo es realizar un estudio exploratorio de las primeras industrias textiles en Bahía instaladas a fines del siglo XIX, como ejemplo notable la Fábrica Todos os Santos, aún en funcionamiento, para contextualizar cómo se dio el crecimiento de esta industria, así como cuáles principales aspectos del crecimiento económico en los siglos XIX y XX. La investigación se realizó con metodología a través de análisis que se basan en un relevamiento del marco teórico de autores de referencia en el desarrollo regional, la revolución industrial y sus más diversas industrias procesadoras, con el fin de recopilar conocimientos sobre el tema y mostrar cómo la industrialización de Bahía influyó en el desarrollo del estado. Los resultados se caracterizan por datos extraídos de investigaciones utilizando la base de datos de la Lista Anual de Información Social (RAIS), del Ministerio de Trabajo y Empleo, con el objetivo de recopilar información sobre la industria textil en Bahía, en el período de 1985 al 2018, y concluyendo demostrando los estudios y esfuerzos realizados en el conocimiento de la materia, relacionando los escenarios con el escenario actual.

Palabras clave: Industria textil, Revolución Industrial, Desarrollo regional, Bahía.

\section{Introdução}

$\mathrm{Na}$ história dos processos evolutivos das indústrias fala-se bastante das revoluções industriais, movimento importante para o desenvolvimento do avanço industrial e para o mercado consumidor, uma vez que a grande maioria dos produtos dos quais são consumidos atualmente advém dos processos industriais, passados pelas diversas fábricas existentes, sejam de têxtil, produtos de higiene, limpeza, e etc. As Revoluções Industriais dividem-se em quatro fases: Revolução Industrial 1.0; Revolução Industrial 2.0; Revolução Industrial 3.0; e Revolução Industrial 4.0, segundo Dathenin (2003), Rifkin (2014) e Schwab, (2016).

O país precursor da primeira Revolução Industrial foi a Inglaterra, seguido de outros países também do continente europeu como Alemanha e França. No Brasil esse processo ocorreu de modo mais lento e atrasado, sendo a Bahia, ainda sendo província no início da primeira revolução industrial brasileira, responsável pelo começo do processo fabril no Brasil, o qual permaneceu por muitos anos como o estado destaque de produção industrial.

O motivo da realização deste estudo é devido a necessidade de discussão acerca do tema que é de importância para o conhecimento histórico da Bahia industrial, bem como para despertar a iniciativa de debate de quais caminhos que foram considerados para que se tenha 
em algum momento atingido a posição destaque perante os demais estados. Essa pesquisa tem como objetivo, levantar informações da indústria têxtil na Bahia, considerando aspectos econômicos que se caracterizaram no final do século XIX e início do século XX, a partir dessas instalações no Estado.

Os dados e resultados da pesquisa foram alcançados utilizando como fonte o banco de dados Relação Anual de Informações Sociais (RAIS) sobre unidades dessa natureza no estado, sendo importante salientar quão diversificada é essa base de dados utilizada para análises. O recorte analítico utilizado é do período de 1985 a 2018, e foi considerado pois é o período o qual a base disponibiliza essas informações e com tais dados da RAIS, foi possível levantar o seguinte leque de informações: 1) a evolução das unidades fabris no estado no período de 1985 a 2018; 2) a distribuição por municípios; 3) as novas indústrias têxteis, segundo o CNAE 2.0 Subclasse; 4) o número de empregos gerados; e 5) a faixa de remuneração média por salários mínimos.

Além dos dados citados, esse estudo se propõe expor informações acerca do momento da indústria têxtil no estado da Bahia de forma a apresentar o processo de industrialização partindo do princípio da mesma, no final do século XIX, onde se aprofunda em identificar as fábricas instaladas no então período e intentando a razão do crescimento da indústria têxtil no estado e conhecer os aspectos do crescimento econômico dos séculos XIX e XX, além de desfiar o exemplo de uma importante fábrica do período em estudo: a Fábrica Todos os Santos, a qual se encontra em atividade.

O trabalho está dividido em quatro partes. A primeira, sendo esta, a introdução do estudo, com a contextualização e apresentação da pesquisa, assim como os seus objetivos. A segunda parte traz o desenvolvimento do trabalho que abordará as informações e dados estudados, que abrange o referencial teórico do estudo, com as abordagens conceituais e a fundamentação da pesquisa sobre a revolução industrial mundial e a revolução industrial no Brasil. A metodologia, está sendo contemplada na terceira parte e demonstra a utilização da abordagem teórica de referencial qualitativo, com a finalidade de pesquisa básica - já que busca estudar um tema do qual tem um quantitativo considerável de estudos tratados e sendo caracterizada, de acordo com os objetivos, em pesquisa descritiva devido aos procedimentos de coleta bibliográfica e documental. Os resultados e discussão constam como a quarta parte do trabalho e trazem informações sobre o processo fabril na Bahia voltado a indústria em estudo, a têxtil, com foco na fábrica têxtil Todos os Santos contextualizando a importância da mesma para diversos aspectos, e sobre o contexto atual de empreendimentos e empregados existentes nas indústrias do ramo têxtil no Brasil e na Bahia no período de 1985 a 2018 
através de dados extraídos da RAIS (Relação Anual de Informações Sociais). A quinta e última traz a conclusão e as principais considerações sobre o estudo, onde aborda questões relacionadas a situação atual do Estado da Bahia no cenário da indústria têxtil, e quais os esforços despendidos e demais ações tomadas diante do ramo têxtil.

\section{Desenvolvimento}

A Primeira Revolução Industrial teve princípio na Inglaterra por volta do final do século XVIII. Logo em seguida alguns países da Europa como, Alemanha e França também iniciaram os processos fabris, e na América do Norte os EUA representava o continente como propulsor desses negócios. Segundo Dathein (2003), esta revolução iniciou quando foi criada a máquina à vapor e a necessidade das construções das ferrovias, em decorrência desta primeira criação surgiram as fábricas têxteis.

Esta revolução foi o impulso principal para que resultasse no desenvolvimento econômico que os países esperavam. Seguindo o raciocínio de Hobsbawm (2001), entende-se, sem questionamentos, que a primeira revolução industrial se deu na Inglaterra, os ingleses dominavam o mercado industrial, em especial no têxtil, onde foram conhecidos como pioneiros no ramo, sempre a frente do desenvolvimento industrial. Portanto, logo após a percepção da concorrência e da então decadência do mercado têxtil, os britânicos começaram a dar seguimento a indústria de carvão e ferro, além de outras indústrias de bens de consumo, já iniciando a segunda fase da revolução industrial, conhecida como Revolução Industrial 2.0, que acontece a partir do final da primeira metade do século XIX e caracterizou-se pelo desenvolvimento na área industrial de telefonia, química, aço, elétrica, petróleo e a produção em massa (Dathein, 2003).

Após a Segunda Revolução Industrial houve muitas mudanças na área fabril devido a necessidade de pesquisa para reerguer o cenário de destruição deixado pelos conflitos. Assim foi caracterizada uma nova era da indústria, a terceira Revolução Industrial, onde trouxe melhores condições de comunicação e processo de produtividade como a Internet. Uma das características dessa nova revolução foi a preocupação com o meio ambiente e a natureza, principalmente nos modos de produção. Essa última característica gerou uma condição marcante da qual continua permeando até os dias atuais, muito conhecida pelas obrigações de responsabilidade ambiental, social e foco na sustentabilidade (Schwab, 2016).

Rifkin (2014) mostra a importância da terceira Revolução Industrial trazendo informações e características da mesma e os benefícios para a sociedade e meio ambiente em 
relação as indústrias adeptas a essa era, de forma que serão capazes de criar áreas de amplos negócios e consequentemente milhões de empregos, sem se deixar de preocupar com a natureza, portanto é um modelo de indústria do qual os dirigentes estarão sempre atentos a interligar o negócio junto ao impacto ambiental. O autor, conhecido por seus estudos da indústria 3.0, ainda afirma que a era 3.0 é o início de esperança para que consigamos ter indústrias mais rentáveis e preocupadas com o entorno do meio ambiente e da sociedade, e que para isto temos "a ciência, a tecnologia e o plano de jogo para que [...] aconteça" (Rifkin, The World Financial Review, p. 8, 30 jun. 2014, tradução nossa).

E atualmente a indústria 4.0, ou a Quarta Revolução Industrial, revolução esta que relaciona as inovações tecnológicas voltadas a automação, controle e tecnologia da informação para melhor desempenho nos processos industriais. "O termo indústria 4.0 é derivado de industrie 4.0. Foi criado na Alemanha no ano de 2011 como uma estratégia de alta tecnologia para o ano de 2020" (Zhou et al; 2015 apud Goulart, 2017. p. 11), que ainda era esperado que a trouxesse melhorias nos mais diversos processos industriais.

Diante desta grande mudança tecnológica, a qual vive-se a Quarta Revolução Industrial ou da chamada Indústria 4.0 o desenvolvimento e a incorporação de inovações tecnológicas estão mudando radicalmente o mundo como o conhecemos e não apenas a indústria, mas a prestação de serviços. "O que torna a quarta revolução industrial fundamentalmente diferente das anteriores é a fusão dessas tecnologias e a interação entre os domínios físicos, digitas e biológicos”. (Schwab, 2016 p. 19)

\subsection{O Brasil e a Revolução Industrial}

As etapas da Revolução Industrial aconteceram de modo mais lento em alguns países, e o Brasil foi um dos países que não conseguiram acompanhar o processo de revolução, mas que teve um bom desempenho diante das condições na qual se encontrava. Enquanto países mais desenvolvidos, por volta dos anos de 1800, estavam vivenciando as características da segunda revolução industrial, o Brasil estava tentando realizar um passo mais largo nos ramos das características da primeira revolução industrial, sendo os têxteis a serem processados industrialmente.

Hardman e Leonardi (1982) recordam e comparam a ascensão da Inglaterra perante as primeiras fábricas no Brasil, no viés de que enquanto a primeira revolução industrial deu início no então país pioneiro em industrialização por volta de mais de metade de um século, o Brasil, ainda colônia, começava a entender a importância do mercado industrial quando 
surgiram as primeiras fábricas, em sua maioria têxtil, em 1830. Sendo, ainda em comparação de quando o Brasil estava já independente de Portugal, os autores anteriormente mencionados ainda relatam, que mesmo o país na época de império brasileiro e mais tarde república, e tido alcançado a melhor fase fabril do país, ainda assim não chegava a ter a qualidade e alta capacidade produtiva dos estabelecimentos fabris que situavam-se na Inglaterra, em especial na região de Lancashire, conhecida como melhor região para produção da matéria-prima têxtil.

Muitos autores como Rebouças (2017) e Cardoso (2013) explicam o motivo da participação tardia do Brasil explorando a essência da dominação portuguesa, porque ainda nesse período, como colônia, os governantes portugueses tinham apenas o território brasileiro como modo de sustento das necessidades do país europeu. Sendo assim, tudo o que era extraído do Brasil era para utilização de Portugal, o que acabou criando uma raiz mercantilista no desenvolvimento do mercado da economia brasileira.

Rebouças (2017) traz um raciocínio de que a forte cultura mercantilista e baseada em exploração extrativista resultou em um embate entre a necessidade de um nascimento industrial e a dificuldade do acompanhamento dos demais países em desenvolvimento. Portanto, resultou nas "dificuldades da industrialização na Província da Bahia a partir das implicações, a médio prazo, das mudanças que se seguiram a 1808" (Rebouças, 2017, p. 4748).

Isso fica claro em vistas, por meio de alguns alvarás expedidos no período do Brasil colônia que ficaram bastante conhecidos no meio do estudo do desenvolvimento industrial brasileiro e baiano devido a clareza do receio de Portugal em tornar o Brasil um reino próprio - à exemplo do alvará de 1785 - registrado em 5 de janeiro, onde proibiu a existência de indústrias têxteis que realizasse produção que não fosse somente de panos e tecidos grossos, dessa forma, passaria a existir fábricas das quais seriam capazes de atender o interesse de Portugal sem que tornasse uma ameaça aos colonos (Azevedo, 2010).

Há uma sequência de fases da industrialização brasileira, e apesar de parecer que o período industrial começou no século XIX, tem-se registro que até chegar nesse século foi preciso muitos anos anteriores engajados na possibilidade de mudança. Com essa visão, alguns autores como Azevedo (2010) afirmam que o processo de industrialização brasileira começou mesmo quando o país ainda estava sob o poder de Portugal, onde existia pequenos aglomerados de características manufatureiras, mas de bastante capacidade produtiva para uma colônia recente. 
Por volta dos anos de 1800 a 1930, os pesquisadores muitas vezes descrevem como um período de libertação para o Brasil, já que estava encaminhando para o ano oficial de independência em 1822 e posteriormente os anos de tentativa de acompanhamento das grandes potências industriais. Entre esse intervalo de anos, foram experienciadas características como mudança de estrutura política, econômica, e estratégias mercantis industriais.

O setor têxtil foi um dos setores que mais teve destaque devido ao crescimento do aumento no plantio e cultivo da matéria-prima essencial, o algodão, além da facilidade na procura da mão de obra, já que o início da industrialização em sua maioria atraia pessoas em busca de oportunidades. Neste último caso, a mão de obra atraída foi dos imigrantes que já tinham conhecimento na área de produção têxtil, o que acabou por favorecer os donos das fábricas. Segundo Stein (1979) apud Fujita, (2015) foi estimado cerca de 48 estabelecimentos industriais em 1882, dos quais estes produziam um total de 20 milhões de metros de tecido por ano, um número que aumentou nos anos seguidos para 134 estabelecimentos presentes em 17 estados.

\section{Procedimentos Metodológicos}

Em todo estudo é importante apresentar os aspectos metodológicos utilizados na investigação. Esta pesquisa possui caráter exploratório, pois busca demonstrar a revolução industrial no âmbito internacional e nacional, com foco, neste último, no estado da Bahia. Além de expor os desafios e sucessos advindos do processo fabril brasileiro e especificamente o baiano, de forma a explicar a importância do processo industrial e a necessidade da industrialização para fins de desenvolvimento regional e nacional. É uma pesquisa de abordagem qualitativa, sendo realizada por meio de levantamento de referencial teórico com base em autores com conhecimento e atuação nos temas abordados, portanto, possibilitando uma melhor explicação e informação. Ainda como contribuição, foram levantados dados secundários da Relação Anual de Informações Sociais (RAIS), considerando o subsetor do IBGE Indústria Têxtil (11) para mostrar o cenário do setor industrial têxtil baiano. O recorte analítico utilizado é do período de 1985 a 2018, e foi considerando, pois é o período o qual a base disponibiliza essas informações e com tais dados da RAIS, foi possível levantar o seguinte leque de informações: 1) a evolução das unidades fabris no estado no período de 1985 a 2018; 2) a distribuição por municípios; 3) as novas indústrias têxtis, segundo o CNAE 
2.0 Subclasse; 4) o número de empregos gerados; e 5) a faixa de remuneração média por salários mínimos.

A metodologia de abordagem teórica tem a finalidade de buscar estudar um tema do qual tem um quantitativo considerável de estudos tratados e é caracterizada, de acordo com os objetivos, em pesquisa descritiva devido aos procedimentos de coleta bibliográfica e documental citados.

\section{Resultados e Discussões}

\subsection{A experiência têxtil na Bahia}

Alguns estudiosos, como Azevedo (2010) relatam os períodos de industrialização desde o início da descoberta do Brasil. Mas diante da análise de que a indústria é muito mais que uma produção restrita, como era tratada na época colonial, e sim uma atividade econômica da qual se engaja em produzir para o desenvolvimento da região onde está inserida, é preciso observar que a industrialização - de fato - ocorreu por volta dos anos de 1800. No caso, era uma produção restrita a Portugal, com todas as limitações precisas quando de conveniência dos portugueses. Sendo assim, o Brasil era apenas meio para enriquecimento externo, sem nenhuma utilidade para o próprio território.

Pelas características mencionadas no parágrafo anterior, é interessante focar que o apogeu, de fato, da indústria brasileira aconteceu por volta dos anos de 1815. Período do qual o Brasil já presenciava grandes possibilidades de tornar-se independente, apesar de já não estar mais caracterizado como uma colônia por causa da vinda da família real portuguesa após a invasão francesa, mas Portugal ainda detinha o domínio das terras brasileiras.

A Bahia, por muito tempo ter sido centro comercial e econômico devido a chegada na região nordeste pelos portugueses, foi o Estado de onde estava toda a criação e desenvolvimento da política econômica da colônia. Apesar de em 1763 ter sido transferida a capital de Salvador (Bahia) para o Rio de Janeiro, medida tomada pelo então Secretário de Estado, Sebastião José de Carvalho e Melo (o Marquês de Pombal) com a ideia de que a nova capital, sendo meio de acesso para contrabando de riquezas minerais em Minas Gerais, dificultaria e combateria "o contrabando e os desvios de ouro e diamantes, no momento em que acontecia uma redução expressiva do recolhimento dos tributos sobre a extração dos metais e das pedras preciosas" (Multirio, 2018). 
Visto que todo o contexto de criação e desenvolvimento da política econômica se encontrava na Bahia, consequentemente o desenvolvimento do ramo industrial se daria no continente do então estado. Além desses fatores, tinha também a condição de que o território baiano era muito rico na produção da principal matéria-prima necessária nas indústrias têxteis, o algodão, as indústrias características da Primeira Revolução Industrial, como também em decorrência da chegada das Naus pela região costeira baiana com escravos e mão-de-obra suficiente para trabalho nas fábricas e engenhos de açúcar.

Assim foi dado início ao desenvolvimento da indústria brasileira, mais especificamente nos anos de 1815. A região baiana, em especial Salvador, já se encontrava com maior parte do parque fabril brasileiro em relação aos demais estados. Já existiam os mais diversos ramos industriais:

Durante boa parte do século XIX, a província abrigava a maioria das fábricas têxteis do Império brasileiro, além de outras fábricas que produziam rapé, charutos, calçados e peças para barcos. Na mesma época, alguns proprietários de engenhos de açúcar, desejosos por reconquistar os mercados estrangeiros, investiram em tecnologia para modernizar a produção (Rebouças, 2017, p. 19)

A década de 1830 foi um período onde mais houve expansão das fábricas têxteis na Bahia, autores como Sampaio (1973) e Sardenberg (1997) descrevem como a partir do ano de 1830 o momento em que inicia o processo fabril têxtil baiano, apesar de já existirem outras fábricas antes desse período, devido o aumento considerável de empresas do setor e do investimento para ampliação e subsídio das indústrias.

A Bahia já se destacava devido ao quantitativo de estabelecimentos têxteis e o reconhecimento destes devido a produção e os produtos que algumas fábricas eram consideradas como padrão de excelência no Brasil. Sardenberg (1997, p. 4) confirma que o início do processo têxtil brasileiro teve início no estado baiano, onde não abrangia uma grande porcentagem quando comparada aos demais estados:

[...] os primeiros surtos desse processo se deram na Bahia, em meados do século passado. De fato, em 1880, cerca de um terço das fábricas de tecidos então operantes no país, estavam localizadas no Recôncavo Baiano, a maioria em Salvador e seus arredores, respondendo elas por cerca de 35\% da produção têxtil nacional (Stein 1957, Azevedo \& Lins 1969).

Cardoso (2004) e Castore (2013) trazem informações que demonstram a diferença entre os demais estados em relação a Bahia nos seus iniciais anos de poderio têxtil, onde em 
1866 o Brasil tinha instalações de oito fábricas deste ramo, e 62,5\% destas estavam localizadas no estado da Bahia.

Em 1844 ocorreu a decisão de implantação de uma política de tarifa bastante conhecida, que teve como objetivo incentivar o mercado industrial brasileiro. A estratégia foi do primeiro ministro Manuel Alves Branco, devido a isso a política tarifária ficou conhecida como Tarifa Alves Branco, de acordo com Barbosa (2014). O incentivo ocorria por meio da isenção de impostos sobre transportes, custos alfandegários, máquinas para produção e peças para indústrias brasileiras. Após os anos seguintes, em 1847 e 1849 respectivamente, houve mais uma isenção e uma taxação, dessa vez para as taxas alfandegárias dos insumos para a produção têxtil e a segunda foi o acréscimo de $2 \%$ em produtos ensacados com algodão que não fosse nacional. Este último tem um ponto interessante porque incentivava os donos das fábricas a realizar investimento em produção do insumo no território nacional.

Entre o período das décadas de 30 e 70 do século XIX, precisamente 1834 e 1844, a Bahia já tinha 10 fábricas têxteis, além de mais um grande quantitativo de fábricas de outros ramos, como rapé, calçados, chapéus, entre outras indústrias de bens de maior demanda na época.

As principais indústrias têxteis da Bahia nesse período, de acordo com sua estrutura e capacidade, assim como contribuição no impacto para o desenvolvimento social onde estavam situadas, são as fábricas: Santo Antônio do Queimado, Conceição, Todos os Santos, Modelo, Nossa Senhora do Amparo, São Salvador, Nossa Senhora do Pilar, São Brás, Nossa Senhora da Penha e São Carlos do Paraguassu.

A primeira fábrica de grande porte, para a época, e de capacidade produtiva considerada industrial, foi a Santo Antônio do Queimado, situada em Salvador. A data de registro dessa fábrica é de 1834, tendo como fundadores o Sr. Paulo Pereira Monteiro e o Engenheiro Joseph Revault. A produção consistia em panos mais grossos focados em sacarias, cobertores e roupas para escravos, além de velas para embarcações mais simples e meias. No início do funcionamento da fábrica, tinha a quantidade de 90 operários.

Conceição foi o nome dado a segunda fábrica de têxteis da Bahia, um ano após a primeira fábrica de mesmo ramo, em 1835 iniciaram as operações da Conceição. A produção era mais focada, apenas pano de algodão. Segundo os estudos de Castore (2013, p. 87), o nome Conceição é devido a localização no "Engenho da Conceição, na então Freguesia da Penha" em Salvador. A quantidade de operários no início da operação não foi identificada, mas após ser adquirida pelo segundo proprietário foi registrado investimentos dos quais registrou-se 60 operários. O empresário fundador da fábrica foi Domingos José d'Amorim, 
porém mais tarde precisou associar-se com outro empresário para que alavancasse os negócios que estavam sofrendo dificuldades, o Senhor Domingos Gomes Ferreira foi o escolhido - sendo mais tarde o único dono da fábrica.

Em 1844 a Fábrica Todos os Santos foi a terceira registrada no ramo industrial têxtil baiano. Essa fábrica possui muitas particularidades positivas das quais ficou conhecida como uma das melhores do Brasil e até mesmo da América-latina, devido a qualidade e capacidade da produção em comparação ao que era exigido e oferecido na época. Localizada no interior da Bahia, no município de Valença, produzia diversos produtos têxteis como panos grossos de algodão traçado para sacos e roupas de escravos e lonas de velas para os mais diversos tamanhos de embarcação. Os fundadores foram Antônio Pedroso de Albuquerque, Antônio Francisco de Lacerda e J. Guillmer, de acordo com Cardoso (2004) e Castore (2013). Tinha 200 operários, um quantitativo muito maior que as demais indústrias já instaladas anteriormente.

Localizada em Salvador, com o total de 180 operários em 1858 - ano do início de operação - a Fábrica Modelo foi uma das maiores da região. Fundada por Manuel Luiz Pinto Coimbra, segundo Cardoso (2004), porém há registros de que em 1858 de acordo com Sampaio (1973) apud (Cardoso, 2004, p. 76) pelo Engenheiro Joseph Revault, produzia dois tipos de panos com qualidades diferentes para sacarias, roupas de escravo e fios para redes.

A quinta indústria estava localizada em Valença, no ano de 1860, e iniciou suas atividades com 90 operários. Os primeiros dirigentes da Fábrica Nossa Senhora do Amparo foram o Sr. Madureira \& Dutra e John Edington, durante essa direção a fábrica produzia uma menor variedade do que viria mais tarde com a direção dos novos donos Moreira, Oliveira e Cia em 1880. Na década de 80, dos oitocentos, a quantidade de operários mais que triplicou, chegando a 300 devido os investimentos realizados pelos novos dirigentes. Segundo Borja (1869) apud (Castore, 2013), a fábrica chegou a ganhar pela segunda vez medalha de ouro devido a qualidade dos panos produzidos, dos quais podiam ser comparados com a semelhança dos panos estrangeiros.

Mais uma fábrica de tecidos se instalava na cidade de Salvador, a Fábrica São Salvador, em 1870. Possuía um quantitativo grande de operários, sendo 150, e os mesmos se empenhavam em produzir os mais diversos produtos que a fábrica oferecia: panos para sacarias, toalhas e guardanapos. Os fundadores foram o Sr. Antônio Francisco Ribeiro Guimarães, segundo os estudos de Rebouças (2017).

Nossa Senhora do Pilar foi a sétima indústria têxtil, localizada em Salvador no ano de 1873, empenhava-se em produzir vários tecidos para sacaria e panos grossos para fardamento 
de escravos e trabalhadores. Os operários chegaram a estar em um quantitativo de 185 durante seu período de funcionamento. Segundo Rebouças (2017), os fundadores foram Catilina e D’Ultra, John Edington foi um dos dirigentes, conhecido por ter atuado como dirigente no ramo têxtil na fábrica Nossa Senhora do Amparo. Pamponet (1975) traz uma informação bastante interessante quanto ao nome da fábrica Nossa Senhora do Pilar, onde é conhecida também como Fábrica Progresso ou Bonfim, este último devido o nome da rua onde estava localizada "no grande prédio sito à Rua do Gasômetro, esquina da Calçada do Bonfim" (Cardoso, 2004, p. 75).

Uma das fábricas mais importantes para a cidade de Salvador devido a grande contribuição na criação de um dos bairros da cidade (bairro de Plataforma), a Fábrica São Braz deu início a suas atividades no ano de 1875 sob fundação e direção de Brandão Jr e Cia, Manoel Francisco de Almeida Brandão e Antônio Francisco Brandão - produzia algodão trançado e mais tarde aperfeiçoou os maquinários e consequentemente aumento a variedade de produtos. A direção da Fábrica São Braz ficou mais conhecida e marcada quando tomada pela família Catharino por causa dos esforços para crescimento e da visão paternalista, onde trouxe alguns benefícios já aplicados pelas indústrias estrangeiras como a criação de uma Vila Operária. A São Braz chegou a operar com um quantitativo de 110 operários, segundo Castore (2013).

A fábrica Nossa Senhora da Penha foi a penúltima das grandes fábricas têxteis existentes na Bahia, fundada em 1875 e localizada na cidade de Salvador, produzia tecidos de lã coloridos e brancos, para sacarias e toalhas. Chegou a operar com 155 operários e teve como os principais dirigentes e fundadores Costa David e Cia, e Sr. Eugenio David. O nome Penha deve-se a localidade na qual a indústria encontrava-se, "na Ribeira de Itapagipe, Freguesia da Penha" (Cardoso, 2004, p. 76).

A última empresa foi a fábrica São Carlos do Paraguassu, fundada em 1876 e estava localizada no município de Cachoeira. O fundador foi o Conselheiro Sr. Luiz Antônio da Silva Nunes. A São Carlos do Paraguassu chegou a operar com 72 operários e tinha como produtos tecidos para sacarias e roupas de panos grossos para trabalhadores.

Além das indústrias têxteis acima listadas, surgiram companhias incorporadoras das quais a maioria das fábricas têxteis foram incorporadas por aquelas, tornando-as maiores no contexto fabril de produção e econômico-financeiro. Essa decisão tomada pelos donos das fábricas permitiu o fortalecimento das mesmas por determinado momento, já que a união de maquinários e mesmo de operários tornava melhor a produção. Nesse momento já estavam, estas indústrias, com grande necessidade de atualização de maquinário, a maioria encontrava- 
se defasado, o que deixava a produção mais lenta e com menos qualidade quando comparada as fábricas que estavam se atualizando.

$\mathrm{Na}$ Bahia, houve diversas incorporações das fábricas. Muitas delas realizaram a inclusão além de fábricas têxteis, mas também com fábricas de calçados, e outros ramos, conforme Rebouças (2017).

A primeira empresa incorporadora foi a denominada Empreza Valença Industrial, fundada em 1887, incorporou as duas fábricas têxteis existentes em Valença (Nossa Senhora do Amparo e Todos os Santos), além de empresas de outros ramos como empresas de fundição de ferro e bronze. Os principais dirigentes foram J. Pinto da Silva Moreira e Domingo Gonçalves de Oliveira. Sendo válido recordar que a fábrica Todos os Santos ainda está em funcionamento, porém com o nome Fábrica Valença, e é possível verificar que a empresa ainda permanece de forma bastante ativa na produção têxtil, inclusive ampliando e adequando de acordo com as demandas do ramo.

A segunda incorporadora foi a Cia União Fabril, dando início ao processo de incorporação das fábricas Santo Antônio do Queimado, Conceição, Modelo, São Carlos do Paraguassu, São Salvador e Nossa Senhora da Penha, em 1891. Alguns dos principais dirigentes já estavam inseridos nas fábricas que foram incorporadas, como Eugenio David e Manoel Luiz Pinto Coimbra, os demais foram Francisco Alvares de Santos Souza, Manoel Antônio de Andrade e Adolpho Malboussion. A junção das fábricas acabou por registrar um quantitativo total de 805 operários.

No mesmo ano da criação da organização incorporadora Cia União Fabril, em 1891, foi fundada a Cia Progresso Industrial da Bahia. Um dos principais dirigentes está os Catharino, e chegaram a possuir um quantitativo de 500 operários na junção total das fábricas incorporadas. Uma das empresas que foram adquiridas fora do ramo têxtil foi a fábrica de calçados que estava instalada no ainda arraial de Plataforma, essa fábrica teve uma boa reputação por causa da qualidade dos seus produtos, segundo Castore (2013).

No ano de 1932 aconteceu uma das maiores incorporações da época devido a quantidade de empresas envolvidas e já incorporadas. A Cia Progresso e União Fabril da Bahia S/A foi a última das incorporadoras têxteis ainda remetente do período de ascensão industrial baiano. Um dos principais dirigentes foi a figura do Bernardo Martins Catharino, conhecido por sua gestão social segundo alguns relatos feitos nos estudos de Sardenberg (1997) e Rebouças (2017).

Cada uma das fábricas trouxe benefícios para o estado baiano, mostrando o poderio fabril da Bahia em dimensões muito mais avançadas do que os demais estados brasileiros. 
Porém, após o desenvolvimento de outros estados, em relação a demanda e maior investimento em infraestrutura e chegada de imigrantes capazes de impulsionar o conhecimento nas instalações fabris, já que muitos deles vinham de países dos quais iniciaram a revolução industrial muito antes da ascensão brasileira no novo ramo econômico, a Bahia entrou em decadência deixando de ser o estado referência nos negócios industriais.

Assim como em todos os países que passaram pela primeira fase da revolução industrial, todos iniciaram com a indústria têxtil: "a trajetória da indústria têxtil no Brasil assim como em países da Europa, América do Norte e Ásia - tem história de aproximadamente 200 anos, e conta com casos de sucesso e insucesso em diferentes épocas com suas respectivas crises" (Fujita, 2015, p. 156-157). Para o Brasil foi um movimento do qual ajudou muito no desenvolvimento do país, já que teve o apoio econômico próprio que precisava quando se tornou independente.

\subsection{Fábricas têxteis importantes para o contexto histórico da Bahia}

A fábrica Todos os Santos e São Braz são umas das mais importantes para o contexto histórico do setor têxtil baiano, a primeira por ter desenvolvido um papel econômico e produtivo de reconhecimento e excelência, e a segunda pelo impacto social positivo nos anos de atuação.

A fábrica São Braz, localizada em Plataforma, um bairro da periferia de Salvador, foi uma das mais importantes na cidade em que foi localizada. Fundada no ano de 1875 por dois irmãos, Manoel Francisco de Almeida Brandão e Antônio Francisco Brandão Jr.

[...] no começo da década de 80 utilizava "uma machina a vapor de força de 40 cavallos", empregando 110 operários em serviço ordinário - sendo 40 homens, 60 mulheres e 10 menores de sexo masculino. [...] naquela época produzia algodão trançado branco e riscado [...] sendo parte dos seus produtos consumida na Bahia e parte exportada para o Norte do Império (Dantas, 1882, apud Castore, 2013, p. 97).

Tinha 110 operários e produzia produtos mais simples como algodão para ensacamento, onde exportava para as províncias do nordeste brasileiro (Rebouças, 2017). Alguns estudiosos analisam o motivo do impulsionamento do bairro de Plataforma devido a instalação da Fábrica São Braz e algumas outras atividades industriais, transformando uma região "rural em bairro operário" (Castore, 2013, p. 150).

No ano de 1891 a Cia Progresso Industrial adquiriu a Fábrica São Braz por meio de incorporação, e em 1959 a fábrica foi desativada devido a insuficiência de continuação das 
atividades fabris. Porém no ano de 1960, houve uma reativação com pouco impacto, já que contava com apenas metade do quantitativo anterior de operários, trabalhando na produção (Sardenberg, 1997). Diante da oportunidade de uma nova abertura graças ao arrendamento realizado à Fábrica de Tecidos Fátima, em 1967, passou a chamar-se de Fatbraz S.A. - ainda assim não conseguindo dar seguimento por muitos anos, então em 1968, um ano após a reabertura com o nome de Fatbraz a fábrica foi fechada e até então (Bevilaqua 1992:36 apud Sardenberg, 1997, p. 7).

Ainda hoje é possível ver a Vila operária no bairro, as escolas, armazéns de secos e molhados e uma população de antigos operários ou de filhos e netos de muitos que são orgulhosos dessa história.

Já a Fábrica Todos os Santos foi fundada em 1844, e está localizada na região do município de Valença. Dentre as três primeiras fábricas têxteis instaladas na Bahia, consta nos estudos como a terceira. Seus fundadores foram J. Guilmer, Antônio Pedroso Albuquerque e Antônio Francisco Lacerda, este último conhecido pelos esforços empreendedores no projeto de construção do Elevador Lacerda (primeiro elevador urbano do mundo). De acordo com Castore (2013) e Rebouças (2017), no início de produção a empresa tinha um quantitativo de 200 operários, e dedicava-se aos mais diversos setores do ramo têxtil, como: produção para roupas de escravos, panos para velas de embarcações entre outros produtos que estavam em procura constante do mercado brasileiro e baiano.

Segundo Pamponet (1975) através dos estudos realizados em obras de Miguel Calmon e Rômulo Almeida, é indubitável a importância da fábrica para a Bahia e Brasil, "ela foi a maior fábrica de tecidos da Bahia no século XIX (até 1891)" e "ficou conhecida como a melhor do Império e talvez Sul-America" (Pamponet, 1975, p. 51).

Em 1887 a Todos os Santos incorporou a mais outras empresas e formou a Empreza Valença Industrial, onde potencializou suas instalações fabris e financeiras.

A instalação foi responsável por gerar renda e emprego na região e como segundo consta no próprio site da empresa, no ano de 1955 ela tinha 1.800, quase o dobro de 1990 (924 empregados), segundo dados da RAIS. No trabalho realizado por Paixão (2006) apenas no período de 1950 a 1980 foram identificados 4.682 registros de trabalho na fábrica Valença:

As fichas analisadas, localizada nos arquivos da Companhia Valença Industrial, dizem respeito às informações funcionais de 4.682 trabalhadores em suas diversas funções: médico, professora, chefes de seção, serventes, tecelões, porteiros, motoristas, enfim, profissionais que atuavam no chão da fábrica têxtil, como também, nos demais setores e empreendimentos da Companhia, quais sejam. (Paixão, 2006, p. 17); 
No mesmo trabalho é enaltecido a importância de Valença para produção têxtil no estado, já que na década de 1870 as duas fábricas existentes na cidade empregavam 430 pessoas que produziam cerca de 1.700.000/ano de tecidos. (Paixão, 2006, p. 30).

Atualmente ainda está em funcionamento e é conhecida como Companhia Valença Industrial, vem realizando investimentos em tecnologia para beneficiamento, com teares, fiação, alvejamento e tingimento.

\subsection{0 fim de um ciclo}

Houve um grande esforço para permitir o desenvolvimento das fábricas têxteis, já que eram as mais importantes da época para o Brasil. A Bahia teve destaque devido a algumas características que autores como Rebouças (2017) e Spinola (2009) ressaltam, como: mão-deobra escrava em grande quantidade, matéria-prima com um bom desempenho produtivo no próprio estado, e as fontes de energias principais para a época, que era a hidráulica.

Na década de 1880 a Bahia já sentia os momentos de decadência industrial e observava a ascensão de outros estados brasileiros como Minas Gerais e Rio de Janeiro, já que ainda em 1866 estava sendo construída ferrovias que ligavam esses estados a outros como São Paulo. Além do mais, o Rio de Janeiro já estava com uma atenção política e econômica desde que a Bahia perdeu a colocação de capital brasileira. Pamponet destaca o momento em que a Bahia deixa de ser exportadora da própria matéria-prima:

O consumo de algodão pelas fábricas de tecidos baianas deveria atingir cerca de 800 a 900 mil quilos em 1875/76. Até esta data grande parte da matéria-prima era oriunda da própria Província, pois a Bahia até então era exportadora de algodão, situação que se modificou daí em diante. Contudo, mesmo neste período, parte do algodão era importado dos estados do Nordeste, pois, parte do algodão produzido na Província, o da região de Caetité, devido às dificuldades de transporte para o Recôncavo, era quase todo enviado para Minas Gerais, através do S. Francisco (Pamponet, 1975, p. 53).

Observa-se que a dificuldade de transporte para a logística de matérias-primas que eram produzidas no próprio estado fez-se necessário a importação de algo que o estado tinha, devido o não investimento em meios de transporte, em especial o ferroviário. Nos estudos da Federação da Indústria e Comércio do Estado da Bahia (FIEB), Fernando Pedrão também traz informações do quanto a Bahia pecou em ter deixado se atrasar no processo fabril têxtil, onde constatou-se extrema necessidade de atualização e implantação de um sistema de transporte. O estado não possuía uma estrada que vinculasse a então capital, Rio de Janeiro, e nem ao 
estado de São Paulo, onde neste último percebia-se a possibilidade de potencial crescimento visto os investimentos realizados e as imigrações com conhecimento técnico de áreas industriais e mercantis. Apenas anos mais tarde foi inaugurada vias terrestres que ligavam o país em maior extensão, sendo a BR 116 em 1967 e a BR 101 em 1972 (FIEB, p. 2013).

Em contrapartida, os motivos para a indústria têxtil ter crescido tanto na região sudeste foi o momento da necessidade cafeeira. Ou seja, cresceu a demanda por produção e ensaque para café, assim como as roupas de escravos e operários da região. Não somente isso, mas também devido a descentralização de poder federativo do qual os estados com maior poder econômico acabaram por favorecer-se - no caso São Paulo e Minas Gerais que neste momento já detinham um crescimento exponencial quando comparado ao estado baiano sobrepondo aos demais estados, além do constante investimento em processos fabris bem mais que o estado da Bahia.

Porém, é preciso concordar que a brecha deixada pela Bahia em não ter investido em malha ferroviária e em atualizações de maquinários e especialização de mão de obra foi um dos motivos mais fortes para que perdesse o posto de estado destaque para estado subdesenvolvido.

A mudança de patamar é um tanto quanto intrigante, devido as grandes oportunidades e o desenvolvimento do qual a Bahia durante o período colonial e principalmente no período Brasil Independência, que houve muitos questionamentos e até mesmo estudos para tentar explicar e entender o motivo da decadência baiana por diversas visões, políticas, econômicas e culturais. Um dos governadores (1946/1950) da Bahia que mais discutiu a situação comparativa do passado e presente do estado foi Octávio Mangabeira, segundo Spinola (2009), quando o então governador assumiu a governadoria viu-se em tamanho espanto com o cenário encontrado que solicitou a Ignácio Tosta Filho - filho do conhecido deputado provincial (1882) Joaquim Inácio Tosta - para que realizasse o primeiro "Plano de desenvolvimento da Bahia, documento pouco divulgado na atualidade e praticamente desaparecido" (Spinola, 2009, p. 83).

Pinto de Aguiar também foi "um dos principais animadores da empolgante discussão que então se travou acerca das razões pelas quais a Bahia perdera o dinamismo econômico" (CDPB, 2008), e se propôs decifrar o "enigma baiano" (expressão criada pelo governador Octávio Mangabeira). O autor Noelio Spinola (2009) traz informações acerca do que foi descoberto pelo intelectual Manoel Pinto de Aguiar sobre o enigma baiano. Entre as causas, Pinto de Aguiar relata as limitações do passado, como a falta de técnicos e o endividamento. Em contrapartida, menciona quais as ações que deveriam ser tomadas de imediato para tentar 
converter o cenário, sendo as principais o controle da economia, dos preços internos e do incentivo aos investimentos e poupança (Spinola, 2009).

No governo Vargas, apesar da Bahia não estar mais em destaque, o país vivenciou um momento de reavivamento da indústria brasileira na tentativa de mudar o enfoque do têxtil e expandir para a área das indústrias pesadas. Esse período ficou conhecido como a Revolução Industrial Brasileira, o patriotismo do presidente Getúlio Vargas (governo 1934/45 e 1951/54) incentivou a industrialização brasileira de forma que não se contentava apenas com as características da Primeira Revolução Industrial, era preciso investir em indústrias de bens de capital. Vargas demonstra em alguns de seus escritos a necessidade de investimento em bens de capital devido a lógica de libertação da importação por insumos e matérias-primas de ferro, já que estes eram a base do que era preciso para suportar os maquinários das indústrias de bens de consumo. Com essa visão, o governo Vargas acabou por possibilitar um grande desenvolvimento na área industrial de bens de capital para o Brasil (Fonseca, 2012).

\subsection{A indústria têxtil contemporânea}

A partir da década de 1960, o processo industrial começa a mudar e acontecem as grandes incorporações, o que de certa forma diminui a mão de obra laboral, a produção e até mesmo a quantidades de fábricas na Bahia, mesmo assim o estado continuou no cenário de produção de tecidos. Atualmente, segundo a Relação Anual de Informações Sociais (RAIS) de 2002 a 2018 sobre a indústria têxtil $(11)^{1}$, que são estratificadas em trinta e um tipos de estabelecimentos, sendo que atualmente existem apenas três indústrias de tecelagem de fibras de algodão, que remetem as primeiras fábricas do período inicial, uma em Valença e duas em Salvador, sendo que em 2006 eram sete. Portanto, quatro delas fecharam ao longo desses doze anos.

A Bahia em 2018 contava com 1.298 estabelecimentos categorizados como da indústria têxtil, distribuídos em 142 municípios, sendo Salvador ainda a primeira em número

\footnotetext{
1 Fazem parte dessa classificação de indústria Têxtil, 31 estabelecimentos classificados pelo CNAE 2.0 subclasse como: Alvejamento, Tingimento e Torção em Fios, Tecidos, Artefatos Têxteis e Peças do Vestuário; Confecção de Peças do Vestuário, Exceto Roupas íntimas e as Confeccionadas Sob Medida; Confecção de Roupas íntimas; Confecção de Roupas Profissionais, Exceto Sob Medida; Confecção, Sob Medida, de Peças do Vestuário, Exceto Roupas íntimas; Confecção, Sob Medida, de Roupas Profissionais; Estamparia e Texturização em Fios, Tecidos, Artefatos Têxteis e Peças do Vestuário; Fabricação de Acessórios do Vestuário, Exceto para Segurança e Proteção; Fabricação de Artefatos de Cordoaria; Fabricação de Artefatos de Tapeçaria; Fabricação de Artefatos de Tecido não Tecido para Uso Odonto-Médico-Hospitalar; Fabricação de Artefatos Têxteis para Uso Doméstico; Fabricação de Artigos do Vestuário, Produzidos em Malharias e Tricotagens, Exceto Meias; Fabricação de Aviamentos para Costura; Fabricação de Equipamentos e Acessórios para Segurança Pessoal e Profissional; Fabricação de Linhas para Costurar e Bordar; Fabricação de Meias; Fabricação de Outros Produtos Têxteis não Especificados Anteriormente; Fabricação de Roupas de Proteção e Segurança e Resistentes a Fogo; Fabricação de Tecidos de Malha; Fabricação de Tecidos Especiais, Inclusive Artefatos; Faç̧ão de Peças do Vestuário, Exceto Roupas íntimas; Facção de Roupas íntimas; Fação de Roupas Profissionais; Fiação de Fibras Artificiais e Sintéticas; Outros Serviços de Acabamento em Fios, Tecidos, Artefatos Têxteis e Peças do Vestuário; Preparação e Fiação de Fibras de Algodão; Preparação e Fiação de Fibras Têxteis Naturais, Exceto Algodão; Tecelagem de Fios de Algodão; Tecelagem de Fios de Fibras Artificiais e Sintéticas e Tecelagem de Fios de Fibras Têxteis Naturais, Exceto Algodão.
} 
com 27\% (354) desse total, seguida por Feira de Santana com 16\% (210) das indústrias do estado, Vitória da Conquista com 4\% (707), Lauro de Freitas 2,6\% (34), Guanambi 2,46\% (32), Santo Antonio de Jesus 23,38\% (31), Jequié 2,23\% (29), Itabuna 2,15\% (28), Itapirucu com 1,85\% (24), em Conceição do Coité com 1,77\% (23), Camaçari e Eduardo Magalhães 1,69\% (22) cada e Porto Seguro 1,54\% (20) indústrias. Dos 142 municípios do grupo, 129 contabilizavam juntos, $30 \%$ (392) estabelecimentos em funcionamento no referido ano.

O Gráfico 1, mostra a evolução de 2002 a 2018 do número de indústrias, sendo que de 2002 a 2011, houve um crescimento de aproximadamente 35\% uma queda de $20 \%$ em relação ao número de 2018.

Gráfico 1 - Indústrias Têxteis (11) - Bahia - Evolução no período de 2002 a 2018 x número de indústrias.



Nota: Fonte: Brasil. (2020). Ministério do Trabalho e Emprego. Programa de Disseminação das Estatísticas do Trabalho. Relação Anual de Informações Sociais (RAIS). Dados de 2002-2018. Fonte: Elaboração própria.

Em relação ao número de empregos gerados nessas indústrias, através da RAIS, foi possível fazer essa identificação. Em 2018 foram 18.867 vínculos informados pelos estabelecimentos, porém esse número foi decorrente a uma redução de $20 \%$ em relação a 2011 (23.328 empregos) anos também de maior número de empresas. O ano de início dessa análise (2002) eram 14.768 empregos, percebe-se um aumento de 20\% para 2011.

O município de Salvador em 2018 possuía 16\% dos empregos nessa indústria na Bahia, seguida por Itabuna e Vitoria da Conquista com 11\% cada, Feira de Santana 9\%, Camaçari $8 \%$ e os municípios de Mata de São João, Valença ${ }^{2}$ e Conceição do Coitè com $3 \%$ cada um e com $2 \%$ os municípios Jequié, Condeuba e Esplanada. Os 121 municípios restantes, juntos somavam $26 \%$ do número de trabalhadores no setor em 2018.

\footnotetext{
${ }^{2}$ Onde possui 7 empresas da Indústria Têxtil
} 
Óbvio que a modernização do maquinário como teares, urdideiras, filatórios, engomadeiras, caldeiras de tingimento e a informatização destas unidades fez com que a necessidade de mão de obra fosse reduzida, que exatamente uma das consequências na revolução industrial, produzir mais com menos mão de obra, mas de fato a Bahia não mais ocupa a posição de prestígio, em número de indústrias é a décima no país com exatamente 13.298 indústrias em 2018. O estado com mais indústrias é São Paulo com 15.163, ou seja, $27 \%$ do total do país, seguido por Santa Catarina com 9.089, Minas Gerais que possui 7.337 indústrias, Pará com 4.794, Rio de Janeiro 3.426, sendo as cinco primeiras. Amapá, Acre e Roraima, ocupam respectivamente a $25^{\circ}, 26^{\circ}$ e $27^{\circ}$ posição nacional em número de indústrias, como mostra o Gráfico 2 abaixo.

Gráfico 2 - Indústrias Têxteis (11) por Estados brasileiros.



Nota: Fonte: Brasil. (2020). Ministério do Trabalho e Emprego. Programa de Disseminação das Estatísticas do Trabalho. Relação Anual de Informações Sociais (RAIS). Dados de 2002-2018. Fonte: Elaboração própria.

Segundo a Associação Brasileira da Indústria Têxtil e de Confecção-Abit, a Produção média do país em 2018 foi de 1,2 milhão de toneladas e 1,3 milhão de toneladas em 2017. Faturamento da cadeia Têxtil e de confecção em 2018 foi de R 176,8 bilhões. O Brasil segundo a Associação, é o quarto maior produtor e consumidor de denim do mundo e quarto maior produtor de malhas do mundo. O que vem a ser posições interessantes, a julgar pelo investimento fabril advindo nos últimos anos.

A Bahia vem buscando ter seu lugar neste setor, segundo estudo da Confederação Nacional das Indústrias - FIEB a Bahia possui como vantagem competitiva, a oferta de fibras e filamentos artificiais e sintéticos, como o poliéster e a poliamida, fabricados no polo petroquímico de Camaçari.

Em 2012 o Governo do Estado buscando fortalecer o setor têxtil e confecções, instalou um Condomínio Bahia Têxtil de uma área de $13.082 \mathrm{~m}^{2}$, que segundo a Superintendência de 
Desenvolvimento Industrial e Comercial - SUDIC foi projetado para abrigar 21 empresas de pequeno porte. Inicialmente foram gerados 800 empregos diretos, e a superintendência espera que quando estiver em pleno funcionamento, crie-se pelo menos dois mil postos de trabalho. Também podemos citar o caso do Polimoda, polo atacadista de moda situado em Feira de Santana com o objetivo de agrupar diferentes empresas do ramo de confecção e criar uma dinâmica para o setor na região. Apoio para inovação e melhoria da produtividade no setor.

Ambos são de produção de vestuário e não de beneficiamento de fibra ou de filamentos, mas que já são iniciativas que ajudam no posicionamento do setor, outrora tão pujante no Brasil.

\section{Considerações Finais}

Como foi mostrada através de informações buscadas para essa pesquisa, a Bahia teve um passado bastante promissor e que quase era difícil acreditar que talvez fosse se tornar um estado fora de destaque do ramo industrial geral e principalmente têxtil.

Conforme o desenvolvimento dessa pesquisa, foi possível perceber que no período dos anos de 1830 a 1880 a Bahia ainda contava com certa vantagem em relação aos demais estados, mas a partir de então houve uma expressiva perda de participação, já que em comparação com os estados brasileiros, Maranhão, Pernambuco, Alagoas, São Paulo, Rio de Janeiro e Minas Gerais, referente os anos de 1866 a 1875 a Bahia permanecia como destaque das fábricas brasileiras de tecidos. Já em 1885, foi possível verificar a perda de posição para Minas Gerais, este último com 13 fábricas e a Bahia com 12.

Somente em 1978 surgiu um sentimento de esperança com a expectativa da Bahia voltar ao cenário industrial brasileiro de forma mais participativa, quando foi iniciado o primeiro Complexo Petroquímico planejado do Brasil (COPEC), localizado no município de Camaçari. A expectativa do governo baiano era de que com a instalação do Complexo fosse possível o desenvolvimento industrial e consequentemente um sistema "autossustentado que deveria superar as limitações setoriais para se inserir, de modo pleno, na economia nacional" (Spinola, 2009, p. 389). Mas não foi possível perdurar com essa expectativa, porque após 35 anos de planejamento e implantação do COPEC não conseguiu alcançar o que fora esperado.

Ainda presente no setor industrial baiano, a indústria têxtil tem uma pequena participação no mercado do estado, em especial Salvador, este no quesito mão de obra é o município que mais emprega trabalhadores desse ramo, conforme dados da RAIS utilizados nesse estudo. Mas ainda quando comparado com outros estados, uma vez já em patamar 
menor que o nosso, é possível perceber que a Bahia ainda precisa de bastante investimento em todas as áreas que compõem o setor industrial, seja de transporte, mão de obra qualificada ou até mesmo de incentivos, que poderão ser atrativos para investimentos.

A indústria têxtil foi para a Bahia, por quase um século, muito importante, movimentou a economia, trouxe o progresso para diversas regiões do estado e atraiu mão de obra e investidores como foram citados no trabalho, ficando um questionamento se existe possibilidade de retomada para esse setor? Ou será mesmo que uma lembrança a ser ter de uma Bahia têxtil?

\title{
Referências;
}

Rifkin, J. (2014). The Third Industrial Revolution: How the Internet, Green Electricity, and 3D Printing are Ushering in a Sustainable Era of Distributed Capitalism. Recuperado de https://www.worldfinancialreview.com.

Sardenberg, C. M. B. (1997). O Bloco do Bacalhau: protesto ritualizado de operárias na Bahia. NEIM/UFBA, Coleção Bahianas.

Schwab, K. (2016). A Quarta Revolução Industrial. São Paulo: Edipro.

Spinola, N. D. (2009). A Trilha Perdida: caminhos e descaminhos do desenvolvimento baiano no século XX. Salvador: Editora UNIFACS.

\section{Porcentagem de contribuição de cada autor no manuscrito}

\author{
Bruna Silva Matos - 50\% \\ Jerisnaldo Matos Lopes - 25\% \\ Rosângela Moreira de Oliveira - 25\%
}

